\title{
Percepción sobre los procesos colaborativos y de participación ciudadana en la zona metropolitana de Puerto Vallarta
}

\section{Perception of Collaborative Processes and Citizen Participation in the Metropolitan Area of Puerto Vallarta}

\author{
Karimen Zamora Sandoval* (iD https://orcid.org/0000-0003-0758-6190 \\ José Luis Cornejo Ortega** (iD http://orcid.org/0000-0001-7965-344X
}

\begin{abstract}
Resumen
Objetivo: analizar, desde la noción de gobernanza participativa, la percepción sobre los procesos colaborativos y de participación ciudadana en la zona metropolitana de Puerto Vallarta (México) de los representantes del sector gubernamental, de los líderes empresariales y de los investigadores. Metodología: investigación cualitativa mediante entrevistas semiestructuradas. Resultados: se deben crear en los municipios conurbados procesos colaborativos eficientes entre el sector público, el privado, la academia y la sociedad civil organizada, así como incentivar una mayor participación proactiva y colaborativa. Limitaciones: no se incluyó en la muestra la sociedad civil. Valor: se enriquece el análisis de la gobernanza en un destino turístico metropolitano interestatal, donde se involucra la participación de un buen número de actores políticos. Conclusiones: no hay un gobierno metropolitano para el desarrollo colaborativo de políticas públicas. Sin embargo, se inició la creación de una estructura de coparticipación entre gobierno y sociedad que necesita monitoreo para evaluar si las decisiones benefician el desarrollo sostenible del destino.

Palabras clave: procesos colaborativos; gobernanza; participación ciudadana; percepción; destino turístico metropolitano; Puerto Vallarta.
\end{abstract}

\begin{abstract}
Objective: to analyze, from the notion of participatory governance, the perception of government sector representatives, business leaders, and researchers on collaborative processes and citizen participation in the Puerto Vallarta Metropolitan Area (Mexico). Methodology: a qualitative research through semi-structured interviews. Results: in the surrounding municipalities efficient collaborative processes must be created between the public, the private sectors, the academy, and the organized civil society, as well as encouraging co-responsibility and greater proactive participation. Limitations: the sample did not include civil society. Value: the enrichment to the analysis of governance in an interstate metropolitan tourist destination, where the participation of a considerable number of political actors is involved. Conclusions: there is no metropolitan government for the collaborative development of public policies, however, progress was achieved in the creation of a government-society partnership structure, which needs to be monitored to evaluate whether the decisions benefit the sustainable development of the destination or not.

Keywords: collaborative processes; governance; citizen participation; perception; metropolitan tourist destination; Puerto Vallarta.
\end{abstract}

Cómo citar: Zamora Sandoval, K., y Cornejo Ortega, J. L. (202I). Percepción sobre los procesos colaborativos y de participación ciudadana en la zona metropolitana de Puerto Vallarta. región y sociedad, el466. doi: I0.22 I98/rys202 I/33/ / 466

*Autora para correspondencia. Universidad de Guadalajara, Centro Universitario de la Costa, Departamento de Ciencias Exactas. Av. Universidad Núm. 203, Delegación Ixtapa, C. P. 48280, Puerto Vallarta, Jalisco, México. Correo electrónico: karimen.sandoval@gmail.com

** Universidad de Guadalajara, Centro Universitario de la Costa, Departamento de Estudios Socioeconómicos. Av. Universidad Núm. 203, Delegación Ixtapa, C. P. 48280, Puerto Vallarta, Jalisco, México. Correo electrónico: jose.luiscornejo@hotmail.com 


\section{Introducción}

Los destinos turísticos metropolitanos conforman un sistema complejo, diverso y dinámico, en el que confluye una multitud de actores o agentes con intereses diversos, por lo cual resulta complicado determinar si éstos convergen en un mismo fin. Puesto que los problemas a enfrentar son muchos y variados, es necesario marcar prioridades. Habrá actores que tengan más incentivos que otros, pero se tiene la certeza de que en algún momento la agenda tocará puntos en los que todos serán recompensados. Para comprender el sistema, hay que analizar sus dos componentes: el primero es el turismo como actividad económica predominante, que comprende un escenario complicado y fragmentado donde coexisten los intereses de múltiples actores: del sector público, del sector privado con subsectores empresariales (hoteleros, restauranteros, prestadores de servicios turísticos), residentes y visitantes del destino.

El segundo es la zona metropolitana de Puerto Vallarta (ZMPV). Ahí interactúan los agentes de las administraciones de los municipios de Puerto Vallarta y Bahía de Banderas, pertenecientes a los estados de Jalisco y Nayarit, respectivamente, donde se resuelven los asuntos públicos transterritoriales. La cuestión es cómo lograr consensos que ayuden a resolver los problemas de manera conjunta. Para ello se necesita información para tomar decisiones que lleven a ejecutar acciones que procuren lo mejor para la metrópoli y para el conjunto de los actores participantes.

Ambos municipios tienen una conciencia compartida de los problemas comunes, pero se necesita más que eso para lograr el consenso, la coordinación, la colaboración y la corresponsabilidad de los actores sociales en los procesos de planificación y gestión orientados a la sostenibilidad de un destino turístico (Adu-ampong, 2014). Los gobiernos municipales y los estatales mantienen su rol directivo, pero necesitan emprender nuevas relaciones con la sociedad más allá de las jornadas electorales (Aguilar, 2013), pues tienen limitaciones que no pueden paliar sin la representación de los actores públicos, privados, de la academia y de la sociedad civil organizada del destino turístico para diseñar estrategias, tomar decisiones y resolver conflictos. Además, gestionar un destino turístico conurbado requiere instrumentos que fomenten la participación, la disposición a compartir, la planificación que tome el pulso de la ciudadanía activa y organizada para llegar a acuerdos que todos cumplan (Pulido y Pulido, 2014).

Los procesos de colaboración ofrecen un mecanismo proactivo para resolver ciertos problemas de planificación relacionados con el desarrollo turístico, y los empresarios del ramo tienen el incentivo para invertir en aquello que les redituará ganancias. Sin embargo, esta clase de proyectos también involucra cuestiones sociales y ecológicas que atañen a la comunidad y que, por lo mismo, necesitan una coordinación mixta; es decir, un engranaje efectivo para que la comunidad participe en la planificación del turismo a través de los representantes de los diversos intereses no sólo privados sino también públicos (Jamal y Getz, 1995). 
La gobernanza es una herramienta clave para lograr dicha colaboración, ya que incorpora a todas las partes interesadas, y cada una de ellas reúne sus habilidades, conocimientos y recursos para el beneficio del conjunto. Además de tener la capacidad y el derecho de participar, está en la balanza la responsabilidad que tienen los actores sociales de intervenir en los procesos de corresponsabilidad y de decidir sobre la gestión del destino turístico en su tendencia a la metropolización, lo cual induce a la cooperación y a la intervención de los agentes interesados, ya sea por razones económicas o por motivaciones sociales o ecológicas (Aguilar y Bustelo, 2010; Kooiman, 1993).

Las preguntas pertinentes son: ¿cuáles son los principales elementos y problemas de gobernanza en la ZMPV? y ¿cuál es la percepción de los procesos de colaboración y de participación ciudadana de la ZMPV? Para responderlas, se analizan las opiniones de tres grupos de informantes clave: los representantes del sector gubernamental, encargados de la planeación y gestión en los gobiernos locales, los líderes empresariales y los investigadores.

\section{Área de estudio}

La ZMPV se localiza en el océano Pacífico y la integran los municipios de Puerto Vallarta en Jalisco y Bahía de Banderas en Nayarit. Por sus características particulares, se la considera la única región conurbada de vocación turística interestatal en México. Ese destino turístico ofrece las playas Las Ánimas, Conchas Chinas, Yelapa, Quimixto, Boca de Tomatlán, Majahuitas, Mismaloya, Los Muertos; Punta de Mita, Lo de Marco, Francisco, Sayulita, Litibú, Destiladeras, Piedra Blanca, La Cruz de Huanacaxtle, Bucerías, Flamingos y Nuevo Vallarta, entre otras. Se ubican ahí las áreas naturales protegidas Los Arcos y el estero El Salado. Quimixto y Yelapa son cascadas y también hacen de albergue de las grutas del Edén. En la zona hay ríos, selva y montañas. Por lo tanto, su flora y su fauna son diversas. Tiene un clima cálido subhúmedo que acobija la Sierra Madre Occidental. Esos recursos han potenciado la diversificación de la oferta, lo cual ha favorecido el turismo alternativo, el cultural, el de congresos y convenciones, la recreación, el descanso y la gastronomía.

La ZMPV tiene 479471 habitantes (Instituto Nacional de Estadística y Geografía [INEGI], 2020). Se ha caracterizado por su dinamismo poblacional constante, pues ha crecido de 1990 a 2000 a una tasa anual de 4.9\%; de 2000 a 2015, de $3.8 \%$; y de 2000 a 2020, de $3.4 \%$, lo que la posiciona en el segundo puesto de zona metropolitana (ZM) de mayor crecimiento, por debajo de la ZM de Cancún (3.9\%) (Zamora y Cornejo, 2020). Esta tendencia demográfica dio origen a la conurbación, y se explica en buena medida por los flujos migratorios de una gran cantidad de trabajadores y turistas residenciales impulsados por la demanda constante de mano de obra en la construcción de hoteles, villas, condominios, desarrollos inmobiliarios, en particular en Bahía de Banderas, municipio en pleno desarrollo turístico (Cárdenas, 2019). Un ejemplo que sobresale es el megaproyecto urbano de Vidanta Riviera Nayarit, complejo de más de 1000 hectáreas (ha) que cuenta con cinco hoteles, dos kilómetros de playa, 28 alber- 
cas, dos canchas de tenis, dos campos de golf y que incluye el Cirque du Soleil para la creación de un parque temático, lo cual convierte dicho megaproyecto en la mayor inversión del sector en México y, por su tipo, el primero en América Latina (Zepeda y Costa de Carvalho, 2018). De manera paralela, se requiere más personal para la atención del turista y para su mantenimiento (Cárdenas y Arellano, 2014).

La ZMPV presenta un alto crecimiento demográfico y urbano promovido por el dinamismo económico del turismo, y concentra 85\% de la población económicamente activa (PEA) en el sector terciario. Pero no ha producido el mismo efecto para mejorar el bienestar ni la calidad de vida de los habitantes; tampoco ha impactado como se quisiera el logro de los objetivos del desarrollo sostenible (ODS) que persigue la Asamblea General de las Naciones Unidas, a fin de consolidar el desarrollo equilibrado entre las cuestiones medioambientales, socioculturales y económicas de la metrópoli. Algunos datos relevantes que dan cuenta de esta situación son:

- Pobreza, desigualdad y marginación. La tasa de pobreza de la ZMPV es de 36\% (ONU [Organización de las Naciones Unidas]-Hábitat, 2018) con respecto al hambre cero. En el caso de las actividades económicas, la mayoría de ellas no genera muchos ingresos, lo que afecta la salud, la educación (índice de 0.672, por debajo del promedio nacional) y el bienestar (Virgen, 2018). Por otra parte, la actividad turística ha ayudado mucho a abatir el desempleo y al incremento de la economía local, con una tasa de ocupación de $97 \%$. Sin embargo, $25 \%$ recibe menos de dos salarios mínimos, lo que evidencia un importante contraste económico y social (ONU-Hábitat, 2018).

- Deterioro del medioambiente. Se registra el aumento en la destrucción de las áreas verdes, la contaminación del agua, el daño a los ecosistemas marinos, la suciedad de las playas y los ríos, la polución del suelo, la erosión, la construcción y la modificación de áreas naturales (Virgen, 2018).

- Desarrollo urbano. El crecimiento urbano anárquico ha desencadenado el déficit de equipamiento urbano, como la pavimentación y el alcantarillado, y ha afectado la movilidad urbana, que tiene un transporte público deficiente. Además, el tratamiento de los residuos y de la basura es insuficiente (Gilabert y Gutiérrez, 2018).

Sin duda, el turismo en sí mismo no impide transitar hacia un destino sostenible. El impedimento se origina en la falta de visión de quienes toman decisiones, tanto del ámbito gubernamental como del sector empresarial. De ahí que colaborar y participar en una zona metropolitana interestatal plantea serias dificultades para resolver los problemas de la conurbación, puesto que México carece de un órgano de gobierno específico para gestionar los problemas de demarcación política en contextos de metropolización. “Añádase a esto que pueden ser gobernadas [las demarcaciones] por partidos de signos diferentes, con calendarios electorales dispares" (Cárdenas, 2019, p. 146). 


\section{Antecedentes}

Un elemento que coincide en la manera en que se gestionan y se dirigen los destinos turísticos y las zonas metropolitanas, es la arbitrariedad de las decisiones referida a los conceptos de gobernabilidad y de dimensión política de la organización, que suponen la capacidad que tiene un sistema para articular las respuestas y las demandas del entorno de manera equilibrada (Camou, 2001). La experiencia de haber tenido gobiernos arbitrarios e inoperantes ha marcado la trayectoria del destino turístico. Por eso es importante construir una gobernanza que neutralice la tendencia que tiene cada nueva autoridad a no proseguir con los proyectos iniciados por la administración que le antecedió y comenzar desde el principio. Esta situación podría contrarrestarse mediante las decisiones participativas. Es decir, la gobernanza participativa y eficiente depende de una gobernabilidad legítima, estable y eficaz.

Aquí conviene la distinción entre gobernanza y gobernabilidad, porque permite comprender mejor el comportamiento de las instituciones de cara a la solución de los problemas públicos. La gobernabilidad alude a la capacidad de los gobernantes de empujar sus agendas con la aceptación de los gobernados (Canto, 2008; Prats, 2005). La gobernanza formula mecanismos de organización basados en la participación ciudadana para formar cogobiernos que tienen las características de horizontalidad, corresponsabilidad y reciprocidad entre gobernantes y gobernados para determinar por dónde comenzar, las formas, las fechas y los costos para ofrecer servicios de calidad y para satisfacer las demandas ciudadanas (Canto, 2016; Porras, 2019).

La gobernabilidad y la gobernanza son estrategias que distribuyen poder y recursos, siempre con el riesgo de malversación y capricho de las autoridades que cambian cada tres años. Los mecanismos participativos y la cooperación público-privada no tienen esa caducidad; su longevidad otorga con frecuencia el mejor conocimiento de la complejidad de la agenda pública, por lo que pueden acumular fuerza para incluir los intereses sociales cuando se definen las políticas municipales y permanecer en el tiempo.

Sin mecanismos de control ciudadano, aumenta la posibilidad de arbitrariedad en el gobierno. No necesariamente por mala fe; a veces la impericia gubernamental se debe al manejo de información deficiente, máxime si ésta es imprecisa, incompleta o está sesgada. A la larga, los fallos en la toma de decisiones se manifiestan en toda clase de asimetrías, como la desigualdad y la inequidad, situación que se ha prolongado porque la ciudadanía no ha podido vencer los numerosos obstáculos que los regímenes autoritarios construyen. Por esa razón los canales de participación no han alcanzado su máxima potencia.

Al menos en la forma, hay acceso a la información o bien la información fluye por canales fuera del control del gobierno. No obstante, incluso en las redes sociales circula información poco pertinente, inoportuna y sesgada. En una gobernanza participativa el proceso es colaborativo. En él intervienen actores gubernamentales, empresarios y de la sociedad civil organizada, y subyace la corresponsabilidad (cada quien desempeña su papel y se compromete con el trabajo que le toca). En esa colaboración cada uno se responsabiliza de que 
se cumplan los objetivos, las metas y se alcancen los niveles adecuados de los indicadores, así como de los resultados de las decisiones que se han tomado. De todo lo anterior surge información confiable, ya que hay supervisión, evaluación y retroalimentación constantes (Flores, 2020).

En algunos destinos turísticos se han registrado niveles bajos de colaboración entre las instituciones de turismo, tanto en el sector público como en el sector público-privado: Chipre (Liasidou, 2018); Kastoriá, Grecia (Dragouni y Fouseki, 2017); Cataluña, España (Soliguer, 2017); y Pueblos mágicos en México (Pulido y Pulido, 2014). ${ }^{1}$

Figura 1. Problematización en la dirección y gestión de los destinos turísticos y de las zonas metropolitanas

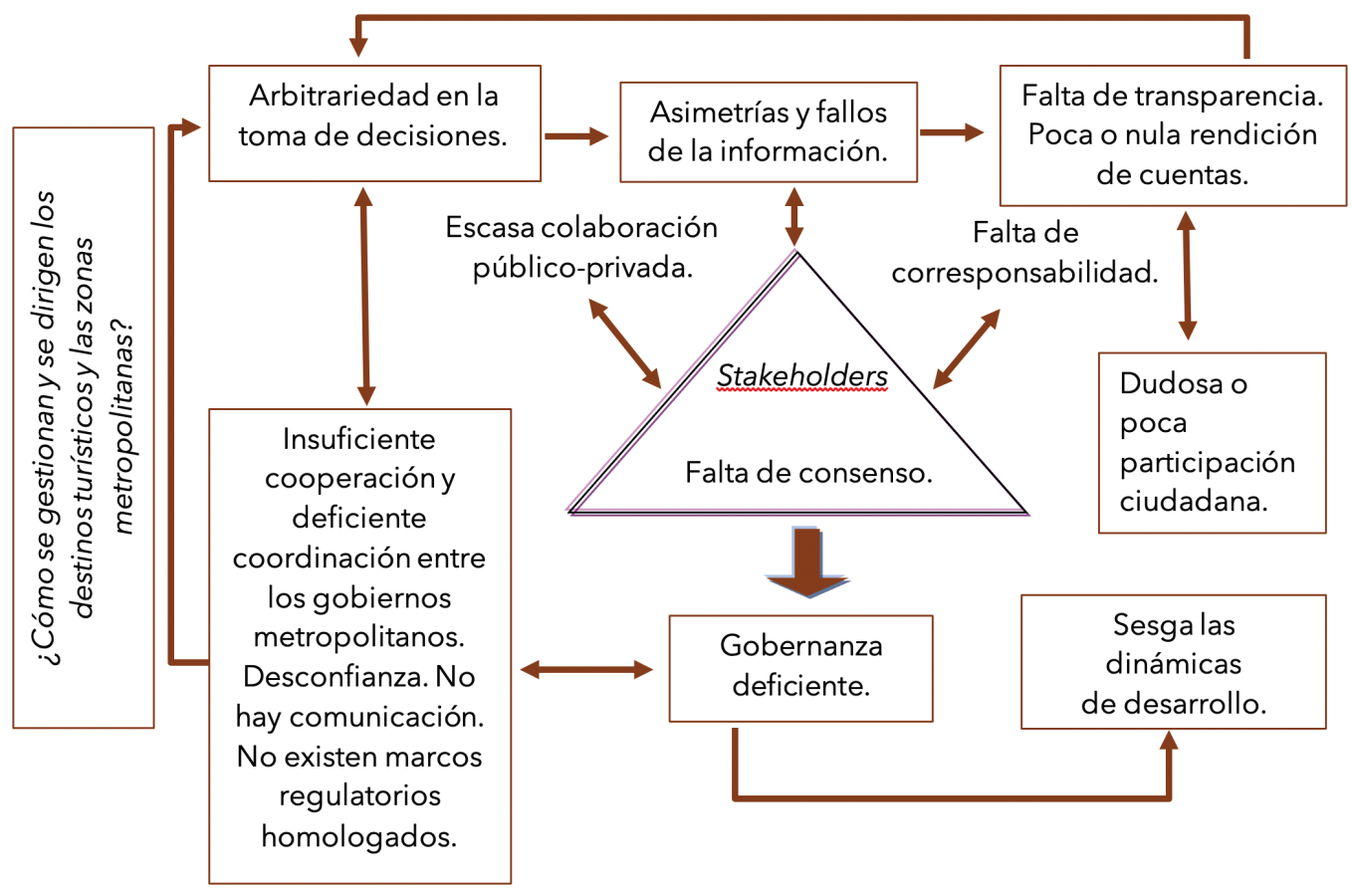

Fuente: elaboración propia con base en la literatura sobre la gobernanza en los destinos turísticos (Adu-ampong, 2014; Dragouni y Fouseki, 2017; Lapeyre, 2011; Paulauskienè, 2014; Pechlaner, Volgger y Herntrei, 2012; Pulido y Pulido, 2014) y en las zonas metropolitanas (Pirlone, Spadaro y Candia, 2017; Tomàs, 2017).

1 Otros ejemplos son: Argentina (Russo y Darmohraj, 2016); Polonia (Strzelecka, 2015); Región Central, Ghana (Adu-ampong, 2014); Lithuania (Paulauskienè, 2014); Zanzíbar, Tanzania (Sharpley y Ussi, 2012); Eppan, Kaltern y Tramin, Italia (Pechlaner, Volgger y Herntrei, 2012); Ámsterdam, Países Bajos y Antalya, Turquía (Erkus, 2011); Río de Janeiro, Brasil (Robterson, 2011); Australia (Wesley y Pforr, 2010); Mar del Plata, Argentina (Barbini, Cacciutto y Cruz, 2007); Alpes suizos (Beritelli, Bieger y Laesser, 2007). 
El compromiso y la responsabilidad de los actores con la comunidad y con la sostenibilidad del destino turístico implican respetar los principios de un régimen democrático para lograr un impacto positivo en la calidad de vida de los gobernados. No obstante, hay un problema y por eso urge identificar los factores que afectan la interacción de los niveles nacional, estatal y municipal de la gobernanza del turismo para determinar la forma de mejorarla, que se produzca sinergia y que se fomente la cooperación entre los actores involucrados (Lapeyre, 2011; Paulauskiené, 2014; Pechlaner, Volgger y Herntrei, 2012). Del mismo modo, es importante conocer la percepción que tenga la comunidad sobre su propia participación en el desarrollo del turismo (Adu-ampong, 2014; Dragouni y Fouseki, 2017; Lapeyre, 2011; Paulauskiené, 2014; Soliguer, 2017).

La débil participación ciudadana en asuntos de interés común es incapaz de exigir que se rindan cuentas y que haya transparencia con respecto a las áreas de opacidad donde la gobernanza tiende a ser deficiente. En particular, esto se manifiesta en la gestión de las zonas metropolitanas, porque una gobernanza ineficiente sesga las dinámicas de desarrollo (Pirlone, Spadaro y Candia, 2017; Tomàs, 2017), más aún si los problemas públicos sobrepasan la circunscripción política institucional, como es el caso de los municipios que pertenecen a diferentes estados y están obligados a resolver los problemas de su conurbación.

En la figura 1 se resumen los principales elementos del desempeño institucional -resultado de los problemas de gobernabilidad y de gobernanza- de los gobiernos metropolitanos y de los destinos turísticos.

\section{Metodología}

El abordaje metodológico para responder a la pregunta de investigación es cualitativo con un enfoque constructivista, basado en la teoría de sistemas autorreferenciales de Niklas Luhmann, en la que se sostiene que un sistema surge de un proceso de reducción de complejidad y que el entorno es más complejo que el sistema mismo, porque aquél no tiene capacidad de autorreflexión y mucho menos de acción (Luhmann, 1990). Esa teoría es una aportación a la comprensión de la naturaleza de los sistemas, en específico de sus posibilidades y de sus límites para la observación de las organizaciones y de las instituciones en su rol de componentes del desarrollo sostenible (Pont, 2013). Asume la hipótesis de que la sociedad se basa en las comunicaciones. En ese sentido, se pregunta si ¿la administración pública es un proceso que resulta de las comunicaciones y del consenso entre los individuos? Cabe destacar que entre los ejes transversales de la gobernanza están la comunicación, la coordinación, la participación y la orientación al consenso. Dichos ejes se relacionan con los procesos de colaboración que se abordan en este estudio de caso sobre los dos municipios que conforman la ZMPV. 
Muestra y criterios de selección

La técnica de investigación que se utilizó fue la entrevista semiestructurada. El tipo de muestreo es no probabilístico: intencional o por juicio, ya que el proceso de selección se basó en escoger personas que conocieran el tema, que tuvieran experiencia, que ocuparan cargos directivos en las áreas estratégicas del fenómeno a estudiar. La tabla 1 presenta los perfiles y los criterios de selección de los tres grupos participantes.

Tabla 1. Perfil de los participantes y el criterio de selección

\begin{tabular}{|c|c|c|}
\hline Participante & Perfil & Criterio de selección \\
\hline $\begin{array}{l}\text { 1. Representantes } \\
\text { del sector } \\
\text { gubernamental }\end{array}$ & $\begin{array}{c}\text { Directivos encargados } \\
\text { de la planeación y gestión } \\
\text { para el desarrollo sostenible } \\
\text { del destino turístico }\end{array}$ & $\begin{array}{l}\text { Directivos en las áreas de } \\
\text { turismo, desarrollo institucional } \\
\text { (planeación), desarrollo } \\
\text { económico, desarrollo social, } \\
\text { medio ambiente } \\
\text { y secretarios generales }\end{array}$ \\
\hline $\begin{array}{l}\text { 2. Líderes } \\
\text { empresariales }\end{array}$ & $\begin{array}{c}\text { Hoteleros, restauranteros } \\
\text { y presidentes de asociaciones } \\
\text { de empresarios }\end{array}$ & $\begin{array}{l}\text { Empresarios de la región } \\
\text { con participación en los } \\
\text { municipios conurbados }\end{array}$ \\
\hline 3. Investigadores & $\begin{array}{c}\text { Investigadores de las } \\
\text { instituciones educativas } \\
\text { de la región }\end{array}$ & $\begin{array}{l}\text { Especialistas y conocedores } \\
\text { de los temas sobre gobernanza, } \\
\text { desarrollo sostenible y turismo }\end{array}$ \\
\hline
\end{tabular}

Fuente: elaboración propia.

Se efectuaron 25 entrevistas en los municipios de Bahía de Banderas y Puerto Vallarta, de las cuales 10 corresponden a los representantes del sector gubernamental, 8 a los líderes empresariales, y 7 a los investigadores. La interacción para conocer sus testimonios se realizó vía telefónica durante agosto, septiembre y octubre de 2020.

Se utilizó el análisis de contenido inductivo en función de los objetivos planteados para el procesamiento de la información. Las entrevistas se transcribieron, y a partir de la lectura, se identificaron las frases que respondían al objetivo de la investigación. Del análisis discursivo emergieron cuatro categorías: 1) elementos de gobernanza (subcategoría: principales problemáticas en la ZMPV); 2) co-gobierno (subcategoría: proceso de colaboración intermunicipal); 3) colaboración pública-privada (subcategorías: convenios de cooperación y proyectos); y 4) proceso de participación ciudadana (subcategorías: mecanismos y promoción de la participación ciudadana; instancia metropolitana de participación ciudadana y políticas e incentivos).

\section{Aspectos éticos}

El protocolo llevado a cabo con los participantes incluyó los siguientes criterios éticos: 1) se les proporcionó mediante correo electrónico una ficha técnica con 
el título de la investigación, los objetivos, la metodología, la justificación y la importancia de la investigación, así como la razón por la que fueron elegidos. Si lo solicitaban, se les hizo llegar un guion con las preguntas de la entrevista; 2) se avaló su autorización para grabar cada entrevista y para que la información que se obtuviera se presentara de forma anónima. Con el fin de salvaguardar la confidencialidad de los informantes, los testimonios se presentan de manera genérica bajo las siguientes etiquetas: representantes del sector gubernamental $(G)$, empresarios (E) e investigadores (I).

\section{Resultados y discusión}

\section{Elementos de gobernanza}

Todos los participantes reconocen la importancia de tener una gobernanza participativa para el desarrollo de un destino turístico metropolitano, bajo un esquema horizontal, en la que todos los sectores deben dirigirse a un objetivo común. A continuación, se enuncian los principales elementos de gobernanza que los grupos analizados consideraron:

\section{1) Homologación del marco regulatorio}

Debido a que es el primer destino turístico conformado en una zona metropolitana interestatal con dos entidades federativas y dos municipios distintos, impera la necesidad de homologar reglamentaciones municipales y estatales para mejorar el tema metropolitano. Y así lo manifestaron los entrevistados:

Lo fundamental será homologar toda la legislación de ambos municipios en materia turística. Para poder ejercer gobernanza, necesitamos primero tener las bases jurídicas y esas no existen. (G)

Ahorita estamos en la fase inicial de que ya somos una zona metropolitana, pero se tienen que homologar todas las reglamentaciones y leyes [...] y lo mejor es a través de un esquema de gobernanza donde a través de cámaras, organizaciones civiles, se conjunten con las asociaciones gubernamentales para llevar las mejores propuestas de homologación, nuevas reglamentaciones para un destino de esta naturaleza. (E)

\section{2) Colaboración y corresponsabilidad}

Fue el segundo elemento coincidente entre los testimonios, en el que se pone énfasis en que, de no existir colaboración con la sociedad civil, con los empresarios, con las diferentes instancias y con los sectores de la sociedad que puedan aportar de manera definitiva, no se lograrían los objetivos. Al respecto, un entrevistado manifiesta que:

La gobernanza es simplemente el trabajo colaborativo entre las autoridades, los gobiernos de todos los niveles con los sectores que forman parte de la cadena productiva, que son el sector empresarial, el sector 
social, incluido cualquier tipo de organización que está formalmente constituida y organizada, y asimismo la participación del sector académico, de las universidades. (E)

Andrew y Phillips (2002) afirman que la gobernanza urbana implica un cambio de jerarquía a la horizontalidad y que el logro de los objetivos de la política depende de la colaboración de múltiples jugadores (sectores público, privado y voluntario) cuyos intereses y responsabilidades se cruzan de manera fluida y contingente (Fontan, Hamel, Morin y Shragge, 2008). Por otra parte, Friedmann (1998) afirma que, en las regiones metropolitanas, los procesos de colaboración entre los diferentes actores preocupados por el desarrollo social y económico de los territorios locales constituyen formas de gobierno local en las cuales la sociedad civil, a través de las organizaciones comunitarias, desempeña un papel importante.

\section{3) Participación ciudadana}

El mayor involucramiento de los ciudadanos en las tareas que antes eran exclusivas del gobierno es otro de los elementos de gobernanza. Los testimonios reflejaron que hay aprecio a la ciudadanía, y todos externaron la importancia de su participación en la solución de los problemas públicos o sociales de la región. Uno de los líderes empresariales lo hace evidente:

La gobernanza consiste en generar mecanismos de participación para la ciudadanía, con la intención de compartir con la población el ejercicio de gobierno, de tal manera que se pueda eficientar el uso de los recursos, las acciones, integrando una corresponsabilidad de los ciudadanos y organizaciones de la sociedad civil a través de un diálogo constante con las autoridades. (E)

Lo anterior conduce a retomar la visión de participación ciudadana entendida como un medio para canalizar una participación más intensa y propiciar el acercamiento entre la ciudadanía y la toma de decisiones (Jiménez y Parra, 2017). Este concepto se extiende al “derecho de grupos y personas a incidir en el espacio público, tanto estatal como no-estatal y es un ingrediente fundamental para la innovación y el fortalecimiento democrático y la construcción de gobernanza" (Hevia y Vergara, 2011, p. 10).

\section{4) Coordinación}

El asunto de la coordinación se consideró una pieza clave para obtener buenos resultados. Uno de los entrevistados señaló:

La coordinación resulta esencial para manejar un mismo nivel de calidad turística y eso tendrá que provocar varias sinergias entre la iniciativa privada, evidentemente de la industria hotelera, que es uno de los sectores más importantes, y los otros sectores relacionados con la misma, con las autoridades municipales, que son el principal contacto en principio, y en segundo lugar, con las autoridades estatales. (G) 
En este sentido, desde una perspectiva institucional, el concepto de gobernanza remite también al problema de la coordinación para gestionar la solución de problemas públicos. De la misma forma, el "desarrollo local y regional está sujeto a sistemas de gobernanza más y más complejos que, a menudo, requieren de nuevas formas de cooperación y coordinación" (Pike, Rodríguez y Tomaney, 2006).

5) Confianza

Uno de los elementos que se consideraron como la base de los demás, es la confianza:

La gobernanza debe mantener o atraer la confianza lo más que se pueda. Ante toda la situación que hemos pasado los ciudadanos, es lo primero que perdemos. Si uno confía en el gobernante que está ahorita, en sus propuestas, es donde el apoyo de los ciudadanos se ve sin ninguna duda. (G)

Para el establecimiento de la confianza, se debe producir una mayor exigibilidad de fortalecer la transparencia y la rendición de cuentas. Prácticas que, a su vez, se fortifican con los procesos de colaboración pública-privada y con la participación ciudadana en la toma de decisiones para la gestión de los destinos turísticos (Gimeno, Tornos, Camp, Longo, Reig, Saz, Losada, Esteve y Rosell, 2018).

6) Información y evaluación

El último elemento identificado alude al acceso a la información y a la evaluación. Así lo expresan:

En primer lugar, una de las cuestiones para la gobernanza significa la información que tenga la población acerca de las diferentes acciones y que pueda caminar hacia un estilo común que realmente nos lleve a seguir adelante. (E)

Sobre este punto, los entrevistados subrayaron que una vez que se transite de la homologación a la práctica de las políticas metropolitanas, será inminente la necesidad de contar con información oportuna, sin asimetrías, eficiente y efectiva, proveniente de la ciudadanía y, después, evaluar los resultados de dichas acciones mediante el establecimiento de reglas compartidas que den cuenta de una gobernanza efectiva y democrática cuya visión se centre en el desarrollo sostenible (económico-social-medioambiental) y que tenga perspectiva metropolitana.

Los tres grupos que se analizaron entienden el concepto de gobernanza. Reconocen que se necesita otro modo de dirigir el destino turístico, que sea gubernamental-social, público-privado y que la planeación, la gestión y la dirección sean de la sociedad en conjunto, sin distinción de municipios, estados o colores partidistas, sino que se entienda como un solo destino. 


\section{Principales problemas de gobernanza}

En la actualidad, el principal problema que se presenta en la ZMPV es la falta de homologación de las reglamentaciones y leyes entre ambos municipios. Algunos ejemplos coincidentes entre los testimonios son:

1. Imagen del destino. El municipio de Bahía de Banderas está repleto de panorámicos, letreros, vendedores ambulantes. En cambio, en Puerto Vallarta eso está prohibido.

2. Equilibrio de las regulaciones sobre los costos de las licencias municipales en torno a la industria restaurantera.

Uno de los problemas es que nosotros no tenemos una central de abastos para ambas ciudades ni contamos con las mismas oportunidades para la instalación de los negocios, de los comercios [...], necesitamos que existan las mismas facilidades y políticamente busquen las coincidencias. (E)

3. Transporte público:

Los taxistas pueden venir de Puerto Vallarta a Bahía, pero no pueden regresarse con pasaje, y a la inversa. Y eso explica que el costo del pasaje sea mayor. Lógicamente, el taxista tiene que asumir el costo. (I)

Desde el lado de Jalisco, Uber, Cabify son legales, y del lado de Nayarit no lo son. (E)

Una ruta de transporte público que entre por la vialidad que conecta a ambos municipios, tiene unas características de un lado, otras de otro. Los permisos, concesiones para el transporte público son válidos de un lado, pero no del otro. (G)

4. Plataformas Airbnb:

En el caso del análisis de Airbnb, si no se trabaja en conjunto, no te sirve de nada tener analizado a Vallarta si no tienes el análisis de Bahía, y viceversa. $(G)$

5. Publicidad o la promoción del destino:

La publicidad o la promoción del destino también debe de ser conjunta. Esto para alcanzar un éxito más inmediato. (E)

Estos asuntos necesitan la homologación de las reglas y de las políticas en asuntos comunes para ambos destinos turísticos, si en verdad éstos desean funcionar como una zona metropolitana que promueve el desarrollo del turismo.

La situación desatada por la pandemia (COVID-19) no sólo puso en evidencia la falta de coordinación entre los gobiernos locales y los estatales, sino que también mostró la falta de conciencia de lo que significa una zona metropolita- 
na y, por lo mismo, no hubo una sola directriz que respondiera a la realidad de ésta. Ambos municipios actuaron por su cuenta, de forma distinta y contradictoria: en un municipio abrieron playas; en el otro se cerraron. En uno se dictó ley seca; en el otro, no. Hay otros casos de esta descoordinación, pero los entrevistados mencionaron con mayor frecuencia los que se acaban de consignar. Uno de ellos expresó:

Se ha visto mucho con lo de la COVID. Se nos había olvidado que somos una zona metropolitana. Bahía de Banderas tenía algunas medidas; Puerto Vallarta con otras. Esto, hasta cierto punto, descontroló a las personas, en la forma en cómo perciben el actuar del gobierno [...]. Desde un inicio se tuvieron que haber tomado decisiones a la par. $(G)$

La falta de acción en conjunto conduce a otra problemática: la desarticulación de los actores. Fue notoria la ausencia de una red de colaboración entre los actores de ambos municipios que pudiera producir contrapeso a los intereses del sector gubernamental, empresarial y social, lo cual confirma lo que se encontró en la revisión de la literatura sobre los bajos niveles de colaboración existentes en los destinos turísticos (Adu-ampong, 2014; Pulido y Pulido, 2014).

Considero que es necesario generar mayor cantidad de mecanismos de colaboración y de órganos a través de los cuales se pueda participar, no sólo emitir nuestros comentarios, sino que éstos se aterricen y formen parte de la toma de decisiones. (E)

El primer problema dentro de la gobernanza, lamentablemente, es que no hay la comunicación correcta entre entes como los de turismo con la gente, sino más bien nos enfocamos más con los empresarios que con los turistas o con la propia gente. $(\mathrm{G})$

También destacaron que la dotación de servicios públicos es uno de los grandes problemas de la ZMPV ante una demandada capacidad en el destino turístico por parte de los hoteles, y los restaurantes, principalmente. La demanda de servicios de agua potable, drenaje y alcantarillado, según los entrevistados, está llegando a un punto crítico, de tal magnitud que el sistema de los servicios municipales podría colapsar si no se planea de forma rigurosa. Sobre este punto, vale la pena mencionar que uno de los testimonios reveló las diferencias que hay en la calidad de los servicios entre ambos municipios.

Había un análisis de Citibanamex que hablaba de la calidad del agua, y se notaba la diferencia, refiriéndose a la calidad del líquido, pero también al abastecimiento. En Puerto Vallarta, ese servicio era satisfactorio, pero en Bahía de Banderas no. No puedes tener esa disparidad en una zona que el turista la asume como una misma. (G) 
Co-gobierno

Proceso de colaboración intermunicipal

El proceso de colaboración entre los municipios de Puerto Vallarta y Bahía de Banderas junto con sus respectivos estados para consolidarse y coordinarse como zona metropolitana, ha pasado por diferentes etapas. La primera data de la década de 1970, cuando se formó la Comisión de Conurbación de la Desembocadura del Río Ameca en 1978. En ese entonces la colaboración dependía de una política vertical que dictaba la federación a través de la Secretaría de Asentamientos Humanos y Obras Públicas (Cárdenas, 2019).

La segunda etapa corresponde a las décadas de 1980 y 1990, cuando empezó una cierta articulación entre los estados y los municipios que apostó por la democratización y la descentralización de las facultades. Esto posibilitó implementar nuevas atribuciones y competencias para que los gobiernos locales, pese a sus debilidades, influyeran en el desarrollo de la región. Sin embargo, los municipios todavía eran muy incipientes y no tenían capacidad de decisión, "manifestándose una ausencia de mecanismos eficaces de coordinación intersectorial e intergubernamental” (Baños, 2013, p. 72).

La tercera etapa comprende de 2000 a 2010, periodo en que se sentaron las bases para una colaboración más institucionalizada mediante la firma del Convenio de Coordinación para la Zona Metropolitana en 2010. Así se crearon los primeros mecanismos formales de coordinación que recibieron el apoyo y el aval de los tres órdenes de gobierno para iniciar una gestión compartida con la finalidad de 1) crear una unidad económica y social, 2) coordinarse y asociarse para una eficaz prestación de los servicios públicos correspondientes, y 3) realizar obras de infraestructura vial, saneamiento, agua potable y alcantarillado (Castro, s. f.). Un hecho importante ocurrió en abril de 2010, cuando el municipio de Bahía de Banderas homologó el huso horario con Puerto Vallarta, con el fin de facilitar las actividades económicas y turísticas de la región, porque representaba un serio problema para los turistas que veían el destino como uno solo y no comprendían que estaban en dos estados con husos horarios distintos.

En el discurso político se manifestaba la necesidad de colaboración entre los dos municipios en relación con los temas sectoriales y de interés común: movilidad, transporte, imagen del destino, seguridad e infraestructura (Baños y Cárdenas, 2013). Para tal efecto, se creó la Comisión de Conurbación de la Zona Metropolitana de Puerto Vallarta-Bahía de Banderas, cuyos objetivos eran definir responsabilidades para la administración y la gestión del ordenamiento metropolitano y la creación del Programa de Ordenamiento de la Zona Metropolitana, con el fin de promover una red metropolitana. Las acciones emprendidas en ese tiempo resultaron insuficientes para la conurbación, porque hubo falta de participación de la sociedad civil, insuficiente homologación entre la legislación urbana de Jalisco y la de Nayarit y escasa capacidad de gestión, coordinación e instrumentación de los gobiernos municipales (Baños, 2013).

La cuarta etapa se inicia a partir del Convenio de Colaboración para la Zona Conurbada y continúa en la actualidad. Destacan dos acontecimientos: en 2015 la Asociación de Empresarios de Puerto Vallarta y Bahía de Banderas, Asociación 
Civil (A. C.) gestionó con ahínco la creación de un consejo coordinador que se regiría como una asociación civil. Su objetivo era consolidar la ZMPV, idea que si bien se tenía desde veinte años atrás, no se había podido realizar con acciones concretas para pasar de un esquema político a lo social o a la actividad turística de la región debido a que no se tenía una visión de gobernanza y se veía constantemente obstaculizada por la falta de homologación en la normatividad de Jalisco y Nayarit, la disparidad de los calendarios político-administrativos y los signos partidistas, lo que impedía llevar a cabo una efectiva gestión metropolitana, a pesar de que en ello habían participado varios actores importantes (Cárdenas, 2018). No fue sino hasta ese momento que se encontró la ruta de trabajo directa con el gobierno federal a través de la Secretaría de Gobernación y la Secretaría de Desarrollo Agrario, Territorial y Urbano (SEDATU) para progresar en la metropolización.

Dos situaciones ocurrieron en diciembre de 2019: la firma de la Carta Intención para el Desarrollo Urbano Regional Sustentable de la Zona Metropolitana de Puerto Vallarta-Bahía de Banderas, y el Convenio Marco de Coordinación para la instalación y funcionamiento de las instancias de gobernanza. Donde los municipios trabajan junto con la federación, a través de la SEDATU, para establecer las instancias de coordinación. De esta forma se consolidó la primera zona metropolitana interestatal turística de México (Ayuntamiento de Bahía de Banderas, 2019).

Respetando el convenio, en marzo de 2020, se llegaron a los primeros acuerdos: la instalación de la Comisión de Ordenamiento Metropolitano, integrada por la federación, los estados y los municipios que conforman la conurbación. Las atribuciones de esta Comisión son coordinar la formulación y la aprobación de los programas metropolitanos, así como su gestión, evaluación y cumplimiento. El organismo puede contar con subcomisiones o consejos integrados por igual número de representantes de los tres órdenes de gobierno (Ley General de Asentamientos Humanos, Ordenamiento Territorial y Desarrollo Urbano [LGAH], 2016, Art. 36).

Al respecto, los entrevistados coinciden en que el desarrollo sustancial de la metropolización se logró debido a la buena relación entre los tres órdenes de gobierno, a la empatía que existe entre los dos alcaldes y a la disposición de ambos gobernadores que, a pesar de provenir de partidos políticos diferentes, se han mostrado muy colaborativos pero, sobre todo, gracias al impulso vigoroso, al compromiso y a la presión constante de grupos ambientalistas, colegios profesionales, la Asociación de Empresarios de Puerto Vallarta y Bahía de Banderas, A. C., la Confederación Patronal de la República Mexicana Puerto Vallarta (COPARMEX PV), el Consejo Coordinador Empresarial de Puerto Vallarta y Bahía de Banderas y la Cámara Nacional de la Industria de Restaurantes y Alimentos Condimentados (CANIRAC), entre otros.

La asociación de empresarios, desde su creación en el año 2000, ya traía esa visión de que el turista y el turismo como actividad primordial no hace diferencia entre municipios o estados, sino que es un destino para ellos desde siempre. Entonces, con esa visión, se tomó también la agen- 
da de la asociación de empresarios [en] este tema de la conurbación. Y cuando se creó este brazo de colaboración entre organismos representativos de la zona, como COPARMEX, CANIRAC o algunos otros organismos, incluso aeropuertos, se pensó que a través de este Consejo Coordinador se pudieran ir sumando de alguna forma voluntarios y esfuerzos para ir dándole forma y retomar lo de la conurbación. (E)

De manera general, los entrevistados han percibido que el proceso de conurbación es muy lento y fallido. Atribuyen ello a 1) la carencia de un marco normativo que contemple los procesos de conurbación interestatal para la conformación de instancias metropolitanas; 2) la debilidad y las restricciones institucionales que enfrentan los municipios para lograr una coordinación efectiva para el entendimiento y la solución de los problemas, en particular los relativos al ordenamiento y a la planeación del territorio y los usos del suelo; y 3) la ausencia de participación social activa en sus órganos de gobierno (Baños, 2013; Cárdenas, 2018).

Un asunto que hay que subrayar es que, pese a que en el discurso político y en el diseño constitucional se pone el énfasis en actuar como zona metropolitana, trabajando sobre la homologación de los marcos regulatorios y en problemáticas comunes, las personas entrevistadas perciben que en realidad no se ha asumido el rol de metrópoli, tal como lo hicieron notar en las principales problemáticas que tiene la ZMPV.

Los estados, aunque han hecho esfuerzos, no han llegado realmente a generar un proyecto colaborativo para esta zona. Se ponen de acuerdo siempre que está sentado ahí el representante del gobierno federal, pero fuera de él no vemos muchos acuerdos. A nivel municipal, sí se ve más colaboración, precisamente por la movilidad, y que afecta a ambos lados de la bahía. Entonces ahí sí hemos visto un poco más de esfuerzos, pero tampoco se han solidificado en un proyecto real que funcione. (I)

Pero, además, los representantes de las autoridades locales también perciben este tipo de situación.

De entrada, ha sido lento. Faltan incentivos de parte de quienes lo están promoviendo, en este caso, el gobierno federal. Le faltan incentivos para que las entidades federativas y los gobiernos municipales se preocupen más por desarrollarse y más por entender cuál es su función respecto a la propia gobernanza y la administración de los recursos. (G)

Una de las creencias que resaltaron algunos actores gubernamentales sobre los motivos por los que en la práctica los municipios y los estados de la ZMPV no se han puesto de acuerdo para ejecutar las mismas acciones en toda la región, ha sido la situación de la pandemia, porque se relaciona con un choque político-cultural. 
La disposición de ambos municipios ha sido buena; sin embargo, estamos enfrentando un choque político-cultural, porque todavía hay celos por parte de los gobernadores, que ven todo desde el punto de vista patrimonialista, que creen que el estado es de ellos. Traen celos y creen que el hecho de tomar decisiones de una forma metropolitana, porque somos dos estados, creen que los estamos desconociendo, que los estamos ignorando, entonces, es una cuestión cultural. (G)

\section{Proceso de colaboración público-privada}

Los representantes del sector gubernamental opinaron que hay muy buena colaboración entre los municipios y el sector empresarial para la realización y la gestión de proyectos en beneficio del desarrollo del destino metropolitano. No obstante, el sentir de los empresarios es que, a pesar de que siempre han sido muy participativos, no se los reconoce ni se los toma en cuenta como quisieran. Además, consideran que son pocos los espacios para colaborar.

Es importante que se involucre más al empresariado donde se tomen decisiones sobre el desarrollo económico, social y algunos otros temas de los municipios [...]. Sí ha habido colaboración de los empresarios con los gobiernos municipales, pero creemos que se les debe dar más reconocimiento a los empresarios por la labor que hacen en los municipios, en las regiones $y$, en especial, en este destino turístico. (E)

La colaboración del sector empresarial en los procesos de planificación y gestión del destino turístico ha sido, en voz de los entrevistados, una buena participación a través de diferentes consejos consultivos. Han recibido invitaciones de los municipios, ha tenido cierta incidencia en las actualizaciones de los planes de desarrollo urbano, tanto de Puerto Vallarta como de Bahía de Banderas, con propuestas escritas. Pero los líderes empresariales comentaron que era necesario tener un mayor involucramiento.

\section{Convenios de cooperación y proyectos}

En la actualidad, no existen convenios de cooperación escritos entre el sector público y el privado como zona metropolitana, sólo son de palabra. Son acuerdos de mutuo interés, pero no se llevan a cabo los procedimientos legales para resolver en conjunto las problemáticas puntuales.

Los convenios de cooperación en sí, directo no los hay. Nos hemos reunido, hemos tenido el apoyo del sector empresarial, los gobiernos han apoyado mucho para sacar adelante que se concrete lo que es la zona metropolitana, pero convenios con el sector empresarial no tenemos.

Actualmente no hay un convenio de cooperación entre el sector público y privado en la región. Se está en la etapa gubernamental de reglamen- 
tos, de leyes, y cuando estén esas reglamentaciones, automáticamente se van a dar las sumas de voluntades con organismos empresariales. (E)

Los proyectos en los que los empresarios han participado de manera activa y en colaboración con los municipios y los estados, son acerca de la promoción turística.

Lo más importante ha sido el asunto de la promoción y es generar un solo espacio para promocionar toda la bahía como atractivo turístico, en el que tú puedas llegar a ese espacio y puedas encontrar desde el proveedor de artesanías hasta el hotel gran turismo que quieras ver, pasando por un restaurante gourmet o de comida típica. Ésta es la propuesta que tenemos con ellos y es en lo que estamos trabajando. $(G)$

Otros temas son la seguridad, el desarrollo de infraestructura, la conservación de zonas verdes (agenda verde), la certificación de playas, los proyectos sociales y la asesoría para la creación de empleos.

Con ellos he tenido una buena alianza para la conservación de la playa y mantenerla limpia y certificada. Con otros hoteleros también se ha tratado de que así sea. Otras veces, ellos nos apoyan muy puntualmente; algunos hoteles, con la conservación de la tortuga marina [...]. Se ha hecho mucho contacto con los empresarios en la región y, a través de ellos, ha sido un vínculo más fácil para crear objetivos y proyectos en común en cuestiones de cambio climático. $(G)$

Otro de los proyectos más impulsados por los empresarios es el de la metropolización.

El tema de la conurbación fue empujado desde COPARMEX en colaboración con la Asociación de Empresarios. (E)

El tema más reciente es la activación económica del turismo y la salud pública ante la pandemia global.

Ahorita estamos con el asunto de los protocolos para la reapertura, con el trabajo de los manuales de operación. (G)

En el tema de la pandemia, los empresarios insistimos en que lo único que puede romper la escala de contagios son los centros de aislamientos voluntarios para aquellos enfermos activos, que están aislados 14 días, y son los de mayor contagio. Y ninguno de los dos municipios fue capaz de entrarle al tema [...]. Yo quiero recordar que, como sociedad civil organizada, tenemos que seguir empujando en todos los proyectos que son de beneficio para la sociedad. (E)

En resumen, algunos líderes empresariales enfatizaron que el principal incentivo es la mejora de la metrópoli para el beneficio de las empresas, la ciuda- 
danía, el turismo y el entorno mediante el involucramiento, y que la industria privada es pieza clave en el desarrollo de la ZMPV. Lo único que desean de parte de los municipios es el respeto de la Ley y la seguridad para la inversión. Dichos líderes asumen el compromiso de participar en la vida pública de la comunidad y contribuir a la resolución de las problemáticas locales.

\section{Participación ciudadana}

Dialogar sobre la participación ciudadana es hablar de gobernanza, es decir, de nuevas formas efectivas y corresponsables para que la planeación y la gestión se conviertan en un sistema de acuerdos políticos en beneficio del destino turístico. En palabras de Iracheta (2016), este enfoque participativo no debería limitarse a ser legislado, sino que además tendría que concretarse en estructuras institucionales participativas, como los institutos de planeación, los observatorios del desarrollo, los consejos deliberativos, las entidades de coordinación intermunicipal, las empresas metropolitanas público-privadas para la movilidad, la infraestructura urbana y otras funciones urbanas que garantizaran la integralidad a largo plazo y la participación desde abajo (Iracheta, 2008). Merino (2013) sostiene que "la participación exige que los representantes políticos refuercen sus lazos de coordinación, entre sí mismos y con la sociedad que los ha elegido, para responder con mayor eficacia a las demandas cotidianas de los ciudadanos" (p. 47).

Para el caso de una zona metropolitana cuya vocación es el turismo, resulta de suma importancia establecer un proceso colaborativo-participativo entre los hoteleros, los restauranteros, los desarrolladores de turismo, los prestadores de servicios turísticos, los transportistas, los grupos ejidales, los grupos vecinales, en fin, los que viven, gozan y sufren el destino turístico, para contar con una participación efectiva, es decir, aprovechar la experiencia y el conocimiento de los distintos actores sociales para el desarrollo sostenible de éste.

\section{Mecanismos de participación y de promoción ciudadana}

Las consultas ciudadanas son mecanismos de participación para la creación de los planes municipales de desarrollo, de las políticas y de los proyectos con impacto en el destino turístico, cuyo objetivo es conocer los temas prioritarios de los ciudadanos en su localidad. Los entrevistados afirman que estas consultas se han aprovechado en la administración, pero aún resultan insuficientes. Su percepción es que la participación es débil y que, en consecuencia, se desaprovechan las experiencias y los conocimientos de los distintos actores sociales para decidir sobre los temas de interés común.

Debería haber más participación, porque no son parejos. Ahorita, por ejemplo, les han dado mucho impulso a los desarrolladores de la industria de la construcción y no nos han dado mucha importancia a los desarrolladores del turismo. Solamente se acuerdan cuando son las elecciones, ahí es donde se hace participar a la ciudadanía para pro- 
yectos políticos. Pero, ya para el desarrollo del destino, el desarrollo urbano, no.

Se debe aprovechar la experiencia, la buena voluntad y en, algunos casos, el conocimiento y los estudios que tienen los propios empresarios para tomar decisiones sobre la región, sobre los proyectos que existan en la zona metropolitana. (E)

Por otra parte, los investigadores coinciden en que la participación social es uno de los indicadores más débiles que hay en todo tipo de proyectos municipales.

Casi siempre son los grupos de interés, los grupos organizados, los que participan y con ello se legitiman los procesos de consultas públicas. ¿Qué quiere decir esto? Que debemos modificar la manera en como se participa socialmente. Porque sí es muy bueno conocer la opinión de expertos, de los grupos de interés, como los hoteleros, restauranteros, los ingenieros, los arquitectos. Sin embargo, no conocemos la opinión de los grupos vecinales. La ciudad se sigue legitimando y validando con la opinión de muy pocos. (I)

En esa triada de gobernanza que es el gobierno, sociedad civil y la empresa, se le ha dado mayor peso a la empresa que a la ciudadanía. Para lograr un desarrollo más equilibrado de los municipios tiene que haber la participación de la ciudadanía [...]. Hace falta que el gobierno busque más compromiso por parte de la ciudadanía. No que los ciudadanos se involucren, sino que el gobierno involucre a la ciudadanía en diferentes aspectos de las políticas públicas. (I)

La percepción de los actores gubernamentales es coincidente, hasta cierto punto, con los empresarios y los investigadores, en el sentido de que hace falta un mayor aprovechamiento de las consultas ciudadanas, cuya importancia reconocen. No obstante, exponen de manera explícita sus buenas experiencias con las consultas ciudadanas en los procesos de planeación.

La participación de cada uno ha abonado. Cuando tuvimos el ejercicio del Plan de Desarrollo Municipal, intentamos hacer un ejercicio novedoso que nos gustó mucho porque tuvimos académicos, empresarios, personas de la sociedad civil. Eso me lo criticaron mucho porque me decían que se me iban a ofender los empresarios o los académicos, porque estaban los señores que veían problemas en su colonia, por ejemplo. Pero de maravilla, porque llegamos a un cruce de ideas, donde no tiene ni toda la razón el ciudadano ni el académico ni el gobierno. Llegamos a un punto en conjunto donde planteábamos problemáticas, soluciones y los compromisos que se iban a llevar ellos en su entorno. (G)

En materia de promoción para la participación ciudadana, se tienen desde los diarios oficiales de los estados, las gacetas municipales y los diarios de ma- 
yor circulación en el estado. En cada una de las delegaciones del municipio y en sus subdelegaciones se colocan todas las convocatorias. Se da mucho apoyo a través de las redes sociales, páginas web y medios oficiales y en los canales tradicionales de radio y televisión.

Creo que debe existir una situación de este tipo, donde se tengan los instrumentos que nos permita consultar al ciudadano desde todo tipo de formas, sean foros abiertos, cerrados, consultas en electrónico, físico, mesas de discusión, debate, mesas de trabajo, planeación de tipo puntual [...]. Es muy importante la participación, y los gobiernos deben crear estos mecanismos, apoyados con el sector académico. $(G)$

Las formas de participación en las que la ciudadanía de la ZMPV se involucra más son las redes sociales y las plataformas digitales. Empero, la mayoría considera que las más eficientes son las mesas de trabajo, ya que de esa manera se puede hacer un análisis más profundo del tema a desarrollar y se puede complementar con la consulta ciudadana a través de otros medios.

\section{Compromiso e interés de los ciudadanos}

Con respecto al compromiso de los ciudadanos de participar en la toma de decisiones para gestionar el destino turístico y orientar su rumbo, se encontraron respuestas divididas. El sector gubernamental argumentó que ha sido un compromiso permanente, activo y fuerte. Los investigadores comentaron que era deficiente, poco e incluso inexistente. Los empresarios coincidían en que si bien el compromiso es fuerte, la participación no es suficiente.

La mayoría de los entrevistados consideraron que no hay ningún interés predominante en la participación de los ciudadanos, sino que más bien hay una mezcla de intereses y que depende del tipo de actor del que se trate. Pero creen que el interés social es mayor, seguido del económico y del interés político, que fue el menos mencionado.

Hay una mezcla de intereses. Efectivamente, si le preguntamos a los turisteros o a los hoteleros, cuál es el interés que los mueve, está claro su interés. De ser competitivos y tener más rentabilidad. Y lo mismo a los restauranteros. Creo que todos tienen una justificación legítima [...], pero también muchas veces movidos por alguna acción antigubernamental o por rechazar alguna acción tienen sus intereses. Entonces, por eso es importante medir la gobernanza, como concilio todos los intereses para que haya un buen proceso de planeación y un buen proceso de gobernanza. Pero sí, efectivamente, cada grupo muestra un interés y desgraciadamente no todos los grupos coinciden en un interés colectivo que beneficie a todos. (I)

\section{Instancia metropolitana de participación ciudadana}

La Ley General de Asentamientos Humanos, Ordenamiento Territorial y Desarrollo Urbano (LGAH) contempla el ámbito metropolitano en la planeación y en 
la gestión urbana del país. Reconoce que la gobernanza metropolitana es una asignatura necesaria y obligatoria en términos de la coordinación del territorio. Esa ley instituye en el artículo 36 que "para lograr una eficaz gobernanza metropolitana, se establecerán los mecanismos y los instrumentos de carácter obligatorio que aseguren la acción coordinada institucional de los tres órdenes de gobierno y la participación de la sociedad" (LGAH, 2016).

El mecanismo de participación ciudadana que establece dicha ley es el Consejo Consultivo de Desarrollo Metropolitano, cuya función es promover los procesos de consulta pública e interinstitucional en las diversas fases de la formulación, aprobación, ejecución y seguimiento de los programas (LGAH, 2016).

Para la conformación de dicho Consejo en la ZMPV, la SEDATU, a través de la Comisión de Desarrollo Urbano y Asuntos Metropolitanos, lanzó una convocatoria en mayo de 2020 para seleccionar a los integrantes de participación ciudadana que conformarían el consejo. Se contempló durante la elección la perspectiva de género y que hubiera representantes de agrupaciones sociales constituidas de forma legal, colegios de profesionales, instituciones académicas y expertos en la materia. El último sector debe conformar mayoría en el consejo, según lo estipulado en la LGAH.

En agosto de 2020, la Comisión de Desarrollo Metropolitano de la región tomó protesta para conformar de manera legal el Consejo Consultivo. Son dieciséis consejeras y consejeros con diferentes perfiles y profesiones, ocho por cada municipio. Ramón Ruelas, consejero de la Comisión, señaló que "con este Consejo se pretende empoderar al ciudadano en las decisiones que se deban de tomar en el desarrollo económico y social de la región" (CPS Noticias Puerto Vallarta, 2020).

Algunos entrevistados comentaron que además del Consejo Consultivo, sería conveniente valorar la creación de áreas alternativas de participación.

Considero que sería muy bueno que se hiciera un instituto de participación ciudadana, porque el Consejo se vuelve algo más técnico, donde asisten más personas con una formación específica que contribuyen en algunas de las áreas de la zona metropolitana, pero un consejo de participación ciudadana le daría la oportunidad a todos de participar, precisamente [en] todos los temas que sean de su interés. (I)

Hasta que no entre en práctica esto, es cuando se va a poder valorar si es suficiente el Consejo Consultivo o si se requiere[n] algunos otros mecanismos. (G)

Por otra parte, los líderes empresariales plantean que, después de haber hablado con los empresarios que mueven la economía de esta región, llegaban a visualizar una figura de autoridad metropolitana, como un gobernador, con su propia autonomía, que tuviera injerencia en toda la región que comprende Vallarta-Bahía de Banderas. 
Esa figura de autoridad pudiera emanar desde la sociedad civil, si realmente los gobiernos quieren darle apertura a la gobernanza y a empoderar a la ciudadanía. (E)

\section{Políticas e incentivos}

Casi todos coinciden en que las políticas para promover la participación de los actores sociales en la gestión del destino turístico son insuficientes, que no se les ha dado seguimiento, que existen pocos espacios de participación y que no hay incentivos.

No existe un proyecto estructurado que incentive a la gente a involucrarse en mecanismos de participación ciudadana. (E)

Brillan por su ausencia. En realidad, no se abre mucho para la participación ciudadana. (I)

Sin embargo, los representantes gubernamentales argumentan que en las políticas está mantener los canales de comunicación directa con los actores sociales, mediante los engranajes establecidos en la planeación municipal. Y que el principal incentivo que se da es la mejora de los espacios públicos y los servicios en sus localidades, tomando en cuenta sus necesidades y respetando sus puntos de vista. Por eso se busca el involucramiento de las diferentes perspectivas, entre ellas, la económica, la comercial y la ambiental.

La percepción común en los testimonios es la consideración de que la principal política para incentivar una mayor participación ciudadana debe encaminarse a que las decisiones políticas (politics) y la política (policy) ${ }^{2}$ sean el producto de las decisiones colectivas, en las que el ciudadano se sienta empoderado, comprometido y corresponsable de los resultados de dichas resoluciones y que la población comprenda que se debe actuar en beneficio de toda la región como un solo destino turístico.

Hay una buena disposición, pero el asunto es que, como ciudadanos, no nos hemos comprometido realmente con el destino, porque priva el interés particular, ya sea del individuo o del gremio, sobre los demás intereses. Entonces, hay que construir una visión colectiva posible, porque podemos construir visiones colectivas utópicas y, en ese sentido, no se concilia lo que realmente se puede hacer. (I)

2 Las decisiones políticas (politics) se refieren al discurso político; es la actividad que realizan distintos grupos para tener acceso al poder estatal y conservarlo; son los rasgos de las relaciones entre gobierno y sociedad, y en función de cómo se dé esta relación serán las políticas gubernamentales (Valenti y Flores, 2009). La política (policy) se vincula a la capacidad del gobierno para intervenir de manera racional en la solución de los problemas públicos (Parsons, 2007), y designa la dimensión técnica de toda decisión social, que se concreta en cursos de acción: ya sea pública o privada dependiendo de los rasgos del proceso de resultados (Bazúa y Valenti, 1993). 
La participación ciudadana no debe ser un evento coyuntural y efímero, sino, por el contrario, necesita estabilizarse en normas e instituciones. En concordancia con el modelo de impacto de la participación ciudadana de Ebdon y Franklin (2006), la ZMPV se encuentra en un "impacto medio" que delega una etapa de discusión, de diálogo para alcanzar consensos, a una exploración de puntos de vista, expectativas e intereses. El siguiente paso es la etapa de involucramiento en las decisiones para compartir responsabilidades, resolver conflictos y formular programas metropolitanos, entre ellos, el Plan de Desarrollo Metropolitano. De este modo se podrá alcanzar la participación de alto impacto o de cogestión, que implica compartir la autoridad y lograr una gobernanza efectiva.

\section{Conclusiones}

En la ZMPV ha habido avances en la firma de convenios y en la homologación de leyes para formalizar la conurbación gracias a la coordinación estrecha entre los alcaldes, los gobernadores y la federación, sin dejar de lado las buenas alianzas entre el sector público y el privado. Lo que no es una realidad es el gobierno metropolitano, porque se han presentado problemáticas. Ejemplos recientes son la situación que ha provocado el COVID-19 y la reactivación económica de la industria turística. Los municipios emprendieron acciones separadas y sin consenso, lo que indica que, en la práctica, no se ha consolidado el proceso colaborativo en el que se tomen decisiones a la par o se lleguen a acuerdos o se apliquen políticas en cuanto que metrópoli para beneficiar el destino.

Lo que sí hay son dos ayuntamientos, presididos por partidos políticos diferentes, que coinciden muy poco y que dependen mucho de las decisiones de sus estados. Debido a que se trata de una zona metropolitana interestatal, y que no es capital de un estado, presenta un doble reto de gestión. El primero implica la coordinación del calendario electoral, en el que haya administraciones que inicien y concluyan en las mismas fechas, con lo que se facilitaría tomar decisiones y que las curvas de aprendizaje fueran paralelas y no divergentes. Y el segundo es encontrar una forma eficiente de transitar del diálogo a un proceso de colaboración, para que se cristalicen las acciones que ejemplifiquen una gobernanza en beneficio del desarrollo armónico y equilibrado de la ZMPV.

A pesar de que hay colaboración público-privada y una coordinación entre los tres niveles de gobierno, todavía no se ha llegado a un proceso colaborativo inclusivo, de ahí que Vázquez-Brust, Piao, Melo, Yaryd y Carvalho (2020) definan la colaboración para el desarrollo sostenible como una "caja negra", en términos de mecanismos de gobernanza colaborativa, para alinear sus esfuerzos hacia objetivos compartidos. Hacen falta espacios y políticas que motiven la participación ciudadana, como una mayor transparencia y rendición de cuentas, con lo que se podría recuperar la confianza del ciudadano para que participe. La administración pública necesita fortalecer la tradición de consultar al ciudadano para incidir en las políticas públicas y de esta forma establecer el compromiso y la corresponsabilidad de los resultados de las decisiones. En la 
actualidad, las minorías validan esas decisiones en la ZMPV y el sector empresarial es el actor predominante en la agenda pública.

Para fomentar un proceso colaborativo entre los actores del destino turístico, más allá de los consejos técnicos recién creados, se necesita que la ciudadanía se organice en más asociaciones civiles para incidir en la toma de decisiones de la ZMPV. Por otra parte, se considera aquí la conveniencia de valorar la dirección de una sola persona que se ubique fuera de los ámbitos y tiempos políticos, que sea una figura de autoridad metropolitana (gobernador o presidente), que tenga autonomía y que a través de los colectivos ciudadanos se estructuren y se definan sus fórmulas de representación interna. Lo anterior podría resultar en el respaldado de la mayoría y en un consenso para que esa persona sea la voz y el representante que coordine ambos municipios y que facilite el diálogo con las administraciones públicas y mejore la interacción y la sinergia.

Prosperar hacia un proceso colaborativo en un destino turístico metropolitano implica que los gobiernos cumplan sus funciones constitucionales dentro de los marcos legales, dictados por políticas metropolitanas y turísticas. Y en el ámbito de la gobernanza, hay asuntos pendientes: determinar la manera en que se integrarían los insumos provenientes de las experiencias y de los conocimientos de la sociedad civil en las políticas públicas y definir en conjunto la mejor estrategia para adaptar los actuales planes municipales a un plan de desarrollo metropolitano. En éste se incorporarían las ideas y las visiones de los diferentes sectores, con lo que se obtendría un mayor compromiso para alcanzar metas, elevar indicadores y desarrollar un buen plan para comunicar los resultados que se vayan obteniendo.

Así debería ser un cuadro de doble entrada: establecer cuáles son las acciones que se llevan a cabo y cuáles son los resultados. Una de las propuestas es crear metodologías, producir datos e indicadores para evaluar los objetivos y las metas institucionales de los planes, las políticas y los proyectos planteados mediante consenso metropolitano y poner en marcha un proceso colaborativo entre el sector público y las empresas del sector turístico, las instituciones educativas, las asociaciones civiles y, en general, con todos los interesados y afectados. Es importante que la mayoría valide los planes, las políticas y los proyectos y que no sea una minoría, como sucede en la actualidad; que se evalúen cuáles son los insumos provenientes de la participación ciudadana y se determine si los resultados de las consultas ciudadanas se integran a las políticas públicas, la forma en que se practican y si los resultados están en favor de la sostenibilidad del destino turístico metropolitano.

Una de las tareas pendientes para futuras investigaciones es realizar análisis-diagnósticos en profundidad sobre la percepción de la comunidad local para participar en las políticas de gobernanza y para contribuir al desarrollo sostenible de un destino turístico metropolitano interestatal, ya que este estudio estuvo limitado a escuchar las voces de tres grupos de actores. Además, resultan necesarios más estudios de casos con características similares a la ZMPV para averiguar si se trata de un estudio paradigmático, aplicable a otros destinos turísticos que se encuentren en una zona metropolitana que involucre a más de una administración. 


\section{Referencias}

Adu-ampong, E. A. (2014). Divided we stand : institutional collaboration in tourism planning and development in the Central Region of Ghana. Current Issues in Tourism, 20(3), 295-314. doi: https://doi.org/10.1080/13683500. 2014.915795

Aguilar, L. (2013). El gobierno del gobierno. México: Instituto Nacional de Administración Pública.

Aguilar, L., y Bustelo, M. (2010). Gobernanza y evaluación: una relación potencialmente fructífera. Gestión y Análisis de Políticas Públicas, 4(2), 2351. Recuperado de https://revistasonline.inap.es/index.php/GAPP/article/ view/437/477

Andrew, C., y Phillips, S. (2002). Urban Affairs: Back on the Policy Agenda. Montreal: McGill-Queen's University Press.

Ayuntamiento de Bahía de Banderas. (2019). Formalizan inicio de la Conurbación Bahía de Banderas - Puerto Vallarta. Recuperado de https://www.bahiadebanderas.gob.mx/x/index.php/2019/01/28/formalizan-inicio-de-la-conurbacion-bahia-de-banderas-puerto-vallarta/

Baños, J. (2013). Consideraciones sobre la gestión metropolitana en México. Acercamiento al caso de la Bahía de Banderas. Trace. Travaux et Recherches dans les Amériques du Centre (64), 69-87. Recuperado de https://www.redalyc.org/pdf/4238/423839522006.pdf

Baños, J., y Cárdenas, E. (2013). La zona metropolitana de Puerto Vallarta. Contexto urbano y políticas de gestión territorial. En A. Arellano e I. Ortiz (coords.), Coordinación y gestión metropolitana en Jalisco (pp. 61-91). México: Universidad de Guadalajara.

Barbini, B., Cacciutto, M., y Cruz, G. (2007). Turismo y gobernanza: implicancias para un desarrollo sostenible. El caso del Ente Municipal de Turismo de Mar del Plata-Argentina. En G. Cruz Jiménez (ed.), Turismo y gobernanza ¿En dónde estamos? Aproximaciones teóricas y empíricas (pp. 65-78). Toluca: Universidad Autónoma del Estado de México.

Bazúa, F., y Valenti, G. (1993). Hacia un enfoque amplio de política pública. Revista de administración pública (84), 25-81. Recuperado de https://www. inap.mx/ portal/images/REVISTA_A_P/rap_84_1993.pdf

Beritelli, P., Bieger, T., y Laesser, C. (2007). Destination governance: using corporate governance theories as a foundation for effective destination management. Journal of Travel Research (46), 96-107.

Camou, A. (2001). Los desafíos de la gobernabilidad. México: FLACSO.

Canto, M. (2008). Gobernanza y participación ciudadana en las políticas públicas frente al reto del desarrollo. Política y Cultura (30), 9-37. Recuperado de http://www.scielo.org.mx/pdf/polcul/n30/n30a2.pdf

Canto, R. (2016). Participación ciudadana, pluralismo y democracia. Revista de Ciencias Sociales, 10(41), 54-75. Recuperado de http://www.scielo.org.mx/ scielo.php? script=sci_abstract\&pid=S1870-69162017000100054\&lng=es\&nr$\mathrm{m}=$ iso 
Cárdenas, E. (2018). Gobernabilidad en las zonas metropolitanas mexicanas. El caso de Puerto Vallarta. Espiral. Estudios sobre Estado y Sociedad, 25(73), 79-120. doi: https://doi.org/10.32870/espiral.v25i73.7003

Cárdenas, E. (2019). Las Zonas Metropolitanas de Acapulco, Cancún y Puerto Vallarta: trayectorias y desafíos. México: Colegio de Jalisco.

Cárdenas, E., y Arellano, A. (2014). La zona metropolitana de Puerto Vallarta: estudio y políticas para una urbe turística de sol y playa. Provincia (32), 71-100. Recuperado de https: / /www. redalyc.org/pdf/555/55538132004.pdf

Castro, F. (s. f.). Propuesta de convenio de colaboración que elaboró y sometió al pleno del Ayuntamiento de Puerto Vallarta.

CPS Noticias Puerto Vallarta. (2020). Recuperado de https://www.youtube. com/watch?V=Xf WAq1DAl1E

Dragouni, M., y Fouseki, K. (2017). Drivers of community participation in heritage tourism planning: an empirical investigation. Journal of Heritage Tourism, 13(3), 237-256. doi: https://doi.org/10.1080/1743873X.2017.1310214

Ebdon, C., y Franklin, A. (2006). Citizen participation in budgeting theory. Public Administration Review, 66(3), 437-447. doi: https://doi.org/10.1111/j.1540-6210.2006.00600.x

Erkus, H. (2011). Modes of tourism governance: a comparison of Amsterdam and Antalya. An International Journal of Tourism and Hospitality Research, 22(3), 307-325.

Flores, M. de l. (2020). Gobernanza participativa, la experiencia de Barcelona. Cuadernos de Vivienda y Urbanismo (13). Recuperado de https://revistas. javeriana.edu.co/index.php/cvyu/article/view/31337

Fontan, J., Hamel, P., Morin, R., y Shragge, E. (2008). Community organizations and local governance in a metropolitan region. Urban Affairs Review, 44(6), 832-856.

Friedmann, J. (1998). The new political economy of planning: The rise of civil society. En M. Douglass y J. Friedman (eds.), Cities for Citizens. Planning and the Rise of Civil Society in a Global Age (pp. 19-35). Londres: John Wiley.

Gilabert, C., y Gutiérrez, N. (2018). Ciudad turística y las múltiples vocaciones productivas. En S. Arnaiz y A. Gómez (coords.), El turismo frente a los objetivos del desarrollo sustentable (pp. 119-140). Puerto Vallarta: Universidad de Guadalajara.

Gimeno, J., Tornos, J., Camp, R., Longo, F., Reig, M., Saz, A., Losada, C., Esteve, M., y Rosell, J. (2018). La gobernanza de los contratos públicos en la colaboración público-privada. Barcelona: ESADE.

Hevia, F., y Vergara, S. (2011). ¿Cómo medir la participación? Creación, validación y aplicación del cuestionario de conductas de participación. México: CIESAS.

Instituto Nacional de Estadística y Geografía (INEGI). (2020). Cuestionario Básico del Censo de Población y Vivienda. Recuperado de http://www.inegi. org. $\mathrm{mx} /$

Iracheta, A. (2008). Transición política y gobernanza territorial en México. En C. Bernárdez, J. Ortiz, y M. Sánchez (eds.), Anuario de espacios urbanos, 
historia, cultura y diseño (pp.173-208). México: Universidad Autónoma Metropolitana (UAM).

Iracheta, A. (2016). La sustentabilidad en México desde la mirada metropolitana. Análisis (2), 1-16. Recuperado de http://library.fes.de/pdf-files/bueros/ mexiko/13015.pdf

Jamal, T., y Getz, D. (1995). Collaboration theory and community tourism planning. Annals of Tourism Research, 22(1), 186-204. doi: https://doi. org/10.1016/0160-7383(94)00067-3

Jiménez, R., y Parra, I. (2017). Experiencias de participación ciudadana en España. Resultados y límites. Ponencia presentada en el VIII Congreso Internacional en Gobierno, Administración y Políticas Públicas GIGAPP. Madrid, España.

Kooiman, J. (1993). Modern Governance. Londres: Sage Publications.

Cámara de Diputados. (2016). Ley General de Asentamientos Humanos, Ordenamiento Territorial y Desarrollo Urbano. Última reforma 1 de junio de 2016. Recuperado de http://www.diputados.gob.mx/LeyesBiblio/pdf/LGAHOTDU_010621.pdf

Lapeyre, R. (2011). Governance structures and the distribution of tourism income in namibian communal lands: a new institutional framework. Revista de geografía económica y social, 102(3), 302-315. doi: https://doi.or$\mathrm{g} / 10.1111 / \mathrm{j} .1467-9663.2011 .00665 . x$

Liasidou, S. (2018). Understanding tourism policy development: a documentary analysis. Journal of Policy Research in Tourism, 11(1), 70-93. doi: https:// doi.org/10.1080/19407963.2018.1465063

Luhmann, N. (1990). Sociedad y sistema: la ambición de la teoría. Barcelona: Paidós.

Merino, M. (2013). La participación ciudadana en la democracia. México: IFE.

ONU-Hábitat. (2018). Índice básico de ciudades prósperas. Informe final municipal Puerto Vallarta, Jalisco. Recuperado de https://onuhabitat.org.mx/ index.php/ indice- de-las-ciudades-prosperas-cpi-mexico-2018

Parsons, W. (2007). Políticas públicas. Una introducción a la teoría y a la práctica del análisis de las políticas públicas. México: Facultad Latinoamericana de Ciencias Sociales.

Paulauskiené, L. (2014). Prospects for improving the governance of tourism in Lithuania: interaction of the national and local levels. Management Theory and Studies for Rural Business and Infrastructure Development, 36(1), 92106.

Pechlaner, H., Volgger, M., y Herntrei, M. (2012). Destination management organizations as interface between destination governance and corporate governance. An International Journal of Tourism and Hospitality Research, 23(2), 151-168. doi: https://doi.org/10.1080/13032917.2011.652137

Pike, A., Rodríguez, A., y Tomaney, J. (2006). Estructuras de entendimiento. Desarrollo local y regional. Valencia: Publicaciones de la Universidad de Valencia. 
Pirlone, F., Spadaro, I., y Candia, S. (2017). Metropolitan governance for territorial cohesion. Journal of Land Use, Mobility and Environment (2), 213-228. doi: https://doi.org/10.6092/1970-9870/4956

Pont, J. (2013). Autorreferencialidad, tecnología y desarrollo sostenible: hacia la autopoiesis reflexiva. Revista Internacional de Sostenibilidad, Tecnología y Humanismo (8), 43-68. Recuperado de https://www.raco.cat/index.php/ Revista Sostenibilidad/article/view/274585

Porras, F. (2019). Gobernanza. Propuestas, límites y perspectivas. Ciudad de México: Instituto de Investigaciones Dr. José María Luis Mora.

Prats, J. (2005). Modos de gobernación de las sociedades globales. En Agustí Cerrillo (coord.), La gobernanza hoy: 10 textos de referencia (pp. 145-172). Madrid: Instituto Nacional de Administración Pública.

Pulido, M., y Pulido, J. (2014). ¿Existe gobernanza en la actual gestión de los destinos turísticos? Estudio de casos. Revista de Turismo y Patrimonio Cultural, 12(4), 685-705. Recuperado de http://www.pasosonline.org/Publicados/12414/PS0414_03.pdf

Robterson, J. (2011). An assessment of collaborative governance in a network for sustainable tourism: the case of RedeTuris. International Journal of Public Administration, 34(5), 279-290.

Russo, N., y Darmohraj, A. (2016). Colaboración público-privada en turismo. Capacidades institucionales en partenariados de gestión turística local en Argentina. Revista del CLAD Reforma y Democracia (65), 157-192. Recuperado de https: / /www.redalyc.org/pdf/3575/357546620006.pdf

Sharpley, R., y Ussi, M. (2012). Tourism and governance in small island developing states (SIDS): the case of Zanzibar. International Journal of Tourism Research (16), 87-96.

Soliguer, A. (2017). Gestión pública socialmente responsable del turismo en Cataluña. Revista de Turismo y Patrimonio Cultural, 15(2), 319-332. doi: https: / / doi.org/10.25145/j.pasos.2017.15.020

Strzelecka, M. (2015). The prospects for empowerment through local governance for tourism. Journal of Rural and Community Development, 10(3), 78-97.

Tomàs, M. (2017). Explaining metropolitan governance. The case of Spain. Raumforschung und Raumordnung, 75(3), 243-252. doi: https://doi. org/10.1007/s1314701604450

Valenti, G., y Flores, U. (2009). Ciencias sociales y políticas públicas. Revista mexicana de sociología (71), 167-191. Recuperado de https://www.redalyc. org/pdf/321/32119200007.pdf

Vázquez-Brust, D., Piao, R., Melo, M. de, Yaryd, R., y Carvalho, M. (2020). The governance of collaboration for sustainable development: exploring the "black box". Journal of Cleaner Production (256), 1-33. doi: https://doi. org/10.1016/j.jclepro.2020.120260

Virgen, C. (2018). Los objetivos del desarrollo sustentable desde la perspectiva de los habitantes de Puerto Vallarta. En S. Arnaiz y A. Gómez (coords.), El turismo frente a los objetivos del desarrollo sustentable (pp. 81-110). Puerto Vallarta: Universidad de Guadalajara. 
Wesley, A., y Pforr, C. (2010). The governance of coastal tourism: unravelling the layers of complexity at Smiths Beach, WesternAustralia. Journal of Sustainable Tourism, 18(6), 773-792. doi: https://doi.org/10.1080/09669581003721273

Zamora, K. , y Cornejo, J. (2020). Limitaciones de los actuales indicadores de gobernanza para medir la calidad institucional en una zona metropolitana con vocación turística. Cimexus, 15(1), 153-173. doi: https://doi.org/10.33110/ cimexus150103

Zepeda, S., y Costa de Carvalho, F. (2018). El desarrollo turístico y la utopía de la sustentabilidad en Bahía de Banderas, Nayarit. En S. Arnaiz y A. Gómez (coords.), El turismo frente a los objetivos del desarrollo sustentable (pp. 101-117). Puerto Vallarta: Universidad de Guadalajara. 